\title{
Çam balı üretici satış fiyatlarının Box-Jenkins modeli ile öngörüsü
}

\author{
Emre Göksua,* (D), Gamze Saner ${ }^{\mathrm{b}}$ (iD)
}

\begin{abstract}
Özet: Çam balı Türkiye'de ihraç edilen en önemli odun dışı orman ürünlerinden biridir. Bu nedenle çam balı fiyatının belirlenerek ileriye yönelik fiyat öngörüsünde bulunulması üretim planlaması için alınacak kararlara yol gösterici bir araç olarak değerlendirilmektedir. Bu araştırmada, çam balı üretiminin en yoğun olduğu Ege bölgesindeki İzmir, Aydın ve Muğla Ticaret Borsaları yıllık tescil bültenlerinde yer alan çam balı üretici satış fiyatları kullanılarak 2021-2025 yılları için reel fiyat $(2003=100)$ öngörüsü yapılmıştır. Araştırmadaki öngörüler için zaman serisi çözümlemelerinde kullanılan Box-Jenkins yönteminden yararlanılmıştır. Oluş̧urulan model sonuçlarına göre, 2021 yılından itibaren çam balı üretici reel satış fiyatlarının dalgalı bir seyir izleyerek düşüş eğiliminde olacağı beklenmektedir. 2020 yılında $4,15 \mathrm{TL} / \mathrm{kg}(2.77 \$ / \mathrm{kg})$ olan ortalama reel bal fiyatının 2025 yılı sonunda \% 18,07 oranında azalarak 3,40 TL/kg $(2.27 \$ / \mathrm{kg})$ seviyesine kadar ineceği öngörülmüştür.
\end{abstract}

Anahtar kelimeler: Çam balı fiyatı, Ticaret borsaları, Zaman serisi çözümlemesi, Box-Jenkins yöntemi, Öngörü, Ege bölgesi

\section{Forecasting of pine honey producer sales prices by using Box-Jenkins model}

\begin{abstract}
Pine honey is the one of the most important non-wood forest products are exported in Turkey. For this reason, determining the price of pine honey and making a future price prediction is considered as a guiding tool for the decisions to be taken for production planning. In this research, real price $(2003=100)$ forecasting for the years $2021-2025$ by using pine honey producer sales prices in the annual registration bulletins of İzmir, Aydın and Muğla Commodity Exchanges in the Aegean region where pine honey production is the most intensively. Box-Jenkins method which is one of techniques used in time series analysis was used for the forecasting in the research. According to the model results, it is expected that starting from 2021, pine honey producer real sales prices will follow a fluctuating trend and will tend to decrease. It is forecasted that the average real honey price, which was $4.15 \mathrm{TL} / \mathrm{kg}(2.77 \$ / \mathrm{kg})$ in 2020 , will decrease by $18.07 \%$ by the end of 2025 and reach the level of $3.40 \mathrm{TL} / \mathrm{kg}(2.27$ $\$ / \mathrm{kg})$.

Keywords: Pine honey price, Commodity exchanges, Time series analysis, Box-Jenkins method, Forecasting, Aegean region
\end{abstract}

\section{Giriş}

Dünya çam balı üretiminin \%90'ının Türkiye'de gerçekleştiği bilinmektedir (Ülgentürk, vd., 2014). Önemli bir odun dışı orman ürünü olarak göze çarpan çam balının esasını Marchalina hellenica Genn. (basra böceği)'in salgıladığı bal özü oluşturmaktadır (Arslan, 2019). Çam balı üretiminde ana etken olan basra böceği doğal yayılışını dünyada sadece Türkiye, Yunanistan ve İtalya'nın Ischia adasında yapmaktadır (Bacandritsos vd., 2004). Basra böceği, Türkiye'de Ege bölgesi başta olmak üzere 5,74 milyon hektar ile genel ormanlık alanın \%25,23'ünü oluşturan Pinus brutia Ten. (kızılçam) ormanlarında (OGM, 2021) yaygın olarak görülen ve ekonomik öneme sahip bir türdür (Ülgentürk vd., 2012).

Türkiye'de en yoğun arıcılık faaliyetlerinin olduğu Ege bölgesinde 2020 yılında, 12.354 adet arıcılık işletmesinde toplam 13.996 ton bal üretimi gerçekleştirilmiştir. Üretim miktarının \%80,31 gibi büyük bir bölümü Muğla (6.103,76 ton), Aydın (3.643,03 ton) ve İzmir (1.493,07 ton) illerinde gerçekleştirilmiştir (TÜİK, 2021). Ege İhracatçılar Birliği (EİB)'nden alınan bilgilere göre 2020 yilında Ege bölgesinden yurtdışına ihraç edilen bal miktarı 2.812,74 ton olup bu miktar 13,35 milyon dolara karş1lık gelmekte (EIB, 2021) ve önemli bir döviz kaynağı olarak görülmektedir.

Orman Genel Müdürlüğü (OGM) tarafından arıcılık faaliyetlerinin desteklenmesi amaciyla 2013-2017 dönemi ve sonrasında 2018-2023 yıllarını kapsayan Bal Ormanı Eylem Planı hazırlanarak yürürlüğe konulmuștur. Yapılan çalışmalar sonucunda günümüze kadar 77.166 hektar alanda 596 adet bal ormanı tesis edilmiştir. Ege bölgesi çam balı üretim alanlarına sahip Muğla, Aydın ve İzmir illerinde ise toplam 12.026,67 ha alanda 33 adet bal ormanı bulunmaktadir (OGM, 2021).

Şengül (2020) tarafindan yapılan bir çalışmada, incelenen işletmelerin Muğla'da \%74,39'unun, Aydın'da \%76,67'sinin ve İzmir'de \%62,16'sının ana gelir kaynağının arıcılık olduğu belirtilmiştir. Dolayısıyla bölgedeki diğer ormancılık faaliyetlerinden yeterince gelir elde edemeyen orman köylerinde yaşayan üreticiler için arıcılık faaliyetinin kırsal kalkınma açısından önem taşıdığı söylenebilir.

Türkiye'de arıcılık büyük bir potansiyel oluşturmasına rağmen kurumsallaşma ve sektör durumuna gelme düzeyine henüz ulaşamadığından içinde bulunulan bu durum ülke

\footnotetext{
$\triangle$ a Ege Üniversitesi, Ziraat Fakültesi, Tarım Ekonomisi Bölümü Doktora Öğrencisi, 35100 Bornova, İzmir

b Ege Üniversitesi, Ziraat Fakültesi, Tarım Ekonomisi Bölümü, 35100 Bornova, İzmir

@ * Corresponding author (İletişim yazarı): goksuemre@ hotmail.com 
arıcılığına ve ekonomisine zarar vermektedir. Diğer taraftan geçmişten bugüne sektörde öne çıkan fiyat odaklı yaşanan sorunların çözülememesinin de arıcılı̆̆ı olumsuz yönde etkilediği bilinmektedir. Türkiye'de bal üretiminde fiyat düşüklüğünün ürün pazarlamasında oluşturduğu bu etkiler yapılan birçok araştırmada vurgulanmıştır. Üreticilerin balını hak ettiği değerden satamadığı ve fiyatların düşük kaldığını belirtenlerin oranını Öztürk vd. (2014) \%37,41, Kadirhanoğulları (2016) \%94,12, Korkmaz (2016) \%42,70, Akyol ve Cazağ (2018) \%94,40, Çevrimli ve Sakarya (2019) $\% 54,80$, Çukur vd. (2019) \%87,50 ve Onuç vd. (2019) $\% 69,81$ olarak belirlemişlerdir. Çam balı sektörünün ana sorunlarından biri fiyat dalgalanmaları ve düşüş eğilimleridir. $\mathrm{Bu}$ nedenle gelecekte oluşacak çam balı fiyatlarının tahmin edilmesi önemli görülmektedir.

Türkiye'de tarım ürünlerinde çok sayıda zaman serisi çözümlemesi ile öngörümleme yapan çalışma (Özer ve İlkdoğan, 2013; Özer ve Yavuz, 2014; Çelik, 2015; Uçum, 2016; Burucu ve Gülse Bal, 2017; Güler vd., 2017; Bars vd., 2018; Saner vd., 2018; Berk ve Uçum, 2019; Yıldız ve Atış, 2019; Caner ve Engindeniz, 2020; Çakan, 2020; Çevrimli vd.,2020) olmasına rağmen orman ürünlerinde sınırlı sayıda çalışmaya rastlanılmış (Kayacan vd., 2013; Esen, 2016; Bayramoğlu, 2018; Göksu ve Adanacığlu, 2018; Şen ve Güngör 2018; Kurt vd., 2018; Kurt ve Karayılmazlar, 2019) ve çam balı ile ilgili zaman serileri çözümlemesine ilişkin bilimsel bir çalışmanın ise bulunmadığı belirlenmiştir.

$\mathrm{Bu}$ araştırmanın amacı, İzmir (ITB), Aydın (ATB) ve Muğla (MTB) Ticaret Borsalarında tescil edilen süzme çam balı üretici satış fiyatlarının kullanılmasıyla 1994-2020 yılları için oluşturulan zaman serisini Box-Jenkins modeli ile çözümleyerek gelecek yıllar için öngörüde bulunmaktır.

\section{Materyal ve yöntem}

Araştırmanın materyalini oluşturan verileri başlıca iki bölüme ayırmak mümkündür. En önemli kaynağı oluşturan ana materyal, ITB, ATB ve MTB tarafindan tescil edilerek y1llık dönemler halinde ilan edilen ve piyasada oluşan cari fiyatları içeren yıllık tescil bültenleridir. İkincil materyal olarak ise Türkiye İstatistik Kurumu (TÜİK), OGM, EİB ve T.C. Resmi Gazete kayıtları, ulusal ve uluslararası araştırma, kitap, tez, rapor, makale ve internet kaynakları kullanılmıştır.

Zaman serisi, değişkenlerin değerlerinin zaman birimlerine (gün, ay, yıl vb.) göre değişimini içeren verilere denilmektedir (Tatoğlu, 2018). Oluşturulan veri setinin söz konusu zaman dönemindeki izlediği gelişimi görme açısından gerekli olan zaman serilerinin çözümlenmesi (Çamoğlu ve Akıncı, 2012), değişkenlerin zaman içerisinde aldıkları değerler içerisinde bulunan örüntülerin anlaşılarak gelecek zamanda alabileceği değerlerin öngörülmesi amacıyla yapılmaktadır (Erturan, 2017).

Araştırma kapsamında bölgedeki fiyat oluşumunu en iyi şekilde temsil etmek amaciyla İTB'deki fiyatlar ile birlikte ATB ve MTB'de oluşan fiyatlar da dikkate alınarak 19942020 yılları arasındaki dönem için tüm ticaret borsalarına ait süzme çam balı ağırlıklı ortalama üretici cari satış fiyatları hesaplanmıştır (Çizelge 1). Zaman içerisinde fiyatlarda meydana gelen oransal değişimleri yıllık dönemler halinde izlemek amacıyla, TÜİK tarafindan her yıl düzenli olarak yayınlanan Yurt İçi Üretici Fiyat Endeksi kullanılmış ve cari fiyatlar 2003 temel yılına $(2003=100)$ göre reel fiyata dönüştürülerek enflasyon etkisinden arındırılmıştır. Oluşturulan 2003=100 temel yıllı zaman serisi reel verileri
Microsoft Excel 2016 ve EViews-11 ekonometri yazılımlarından yararlanılarak çözümlenmiştir.

Zaman serileri çözümlemesinde kullanılan yöntemler; çok değişkenli ve tek değişkenli zaman serileri ile tahmin yöntemleri olmak üzere iki gruba ayrılmaktadır. Çam balı üretici satış fiyatının gelecek yıllara ilişkin öngörüsünde tek değişkenli zaman serilerinde kullanılan, ileriye yönelik tahminleri istatistiksel yöntemlerle yapan tekniklerden biri olan Box-Jenkins tahmin yöntemi (ARMA Modelleri) kullanılmıştır. $\mathrm{Bu}$ yöntemin uygulanabilmesi için zaman serisinin; kesikli, durağan ve eşit aralıklı gözlem değerlerinden oluşması gerekmektedir (Akdağ ve Yiğit, 2016). Otoregresif (AR-Auto-Regressive), hareketli ortalama (MA-Moving Average), AR ve MA modellerinin karışımı olan Otoregresif Hareketli Ortalama (ARMA-Auto Regressive Moving Average) modelleri en genel doğrusal durağan Box-Jenkins modelleridir (Ataseven, 2013).

Durağan bir zaman serisi ARMA (p,q) Eşitlik (1)'deki gibi modellenebilir;

$$
\begin{aligned}
& \mathrm{Y}_{\mathrm{t}}=\phi_{1} \mathrm{Y}_{\mathrm{t}-1}+\phi_{2} \mathrm{Y}_{\mathrm{t}-2}+\ldots+\phi_{\mathrm{p}} \mathrm{Y}_{\mathrm{t}-\mathrm{p}}+\varepsilon_{\mathrm{t}}-\Theta_{1} \varepsilon_{\mathrm{t}-1}-\Theta_{2} \varepsilon_{\mathrm{t}-2}-\ldots-\Theta_{\mathrm{q}} \\
& \varepsilon_{\mathrm{t}-\mathrm{q}}
\end{aligned}
$$

Burada $p(A R)$ derecesini, $d$ bütünleşme derecesini ve $q$ (MA) derecesini göstermektedir. $Y_{t}$ d'inci dereceden farkı alınmış $\mathrm{t}$ zamanındaki gerçek değer, $\varepsilon_{t}$ hata terimi, $\phi_{i}$ $(i=1,2, \ldots, p)$ ve $\Theta_{j}(j=0,1,2, \ldots, q)$ model parametreleridir (Akay vd., 2019).

Zaman serilerinin modellenmesi ve öngörülmesi için kullanılan bu yöntemin ön koşulu durağanlıktır (Oruç ve Eroğlu, 2017). Araştırmada, öncelikle oluşturulan serinin durağan olup olmadığını belirlemek amacıyla Genişletilmiș Dickey-Fuller (Augmented Dickey Fuller-ADF) Birim Kök testi uygulanmıştır (Dickey and Fuller, 1981). Ayrıca otokorelasyon fonksiyonu (ACF) ve kısmi otokorelasyon fonksiyonu (PACF) grafikleri de çizilerek serinin ne tür bir gelişim içerdiği görsel olarak da belirlenmeye (korelogram) çalışılmıştır.

Model oluşturma aşamasında değişkenler belirlendikten sonra elde edilen modelde otokorelasyon olup olmadığ denetlenmelidir (Özer ve Yavuz, 2014; Saner vd., 2018). Bu araştırmada modellerdeki otokorelasyon denetimi için LjungBox Q testi uygulanmış ve $\mathrm{H}_{0}=$ "otokorelasyon yoktur" hipotezi test edilmiştir (Ljung ve Box, 1978). Modele ait kalıntı değerlerinin normal dağılıma uygunluğunun denetlenmesi ise grafiksel incelemelerin yanında ShapiroWilks normallik testi ile değerlendirilmiştir.

İncelenen ticaret borsalarında oluşan çam balı üretici reel satış fiyatını, en az hata ile yansıtan tahmin gücü yüksek modellerin belirlenmesi için çok sayıda model denemesi gerçekleştirilmiştir. Ortaya çıkan modellerin uygunluğunun belirlenmesi için Ortalama Mutlak Yüzde Hata (MAPE) istatistiği (Oruç ve Eroğlu, 2017) değerinin \%20'nin altında olmasına dikkat edilmiştir. Theil Eşitlik Katsayısı (Theil's U) değerlerinin ise mümkün olduğunca 1 'den küçük çıkması gerekmektedir (Özer ve İlkdoğan, 2013; Saner vd, 2018; Çakan, 2020). Ayrıca “Akaike Bilgi Ölçütü” (AIC), HannanQuinn Ölçütü” (HQC) ve Schwarz-Bayesçi Bilgi Ölçütü” (BIC) değerlerinin ise diğer modellere göre en düşük olanları dikkate alınmıştır (Yalta, 2011; Güler vd., 2017; Saner vd., 2018; Caner ve Engindeniz, 2020). 


\section{Bulgular}

Üretici eline geçen süzme çam balı reel satış fiyatı serisine ait modelleme yapmadan önce serinin durağan olup olmadığı ADF Birim Kök testi ile denetlenmiştir. Sabit terimli ve eğilimli ADF Birim Kök testinden ortaya çıkan bulgulara göre fiyat değişkeninin $\% 1, \% 5$ ve $\% 10$ anlamlılık düzeyinde durağan olduğu belirlenmiştir (Çizelge 1).

Çam balı fiyatlarına ait serinin öngörü modelinin oluşturulmasında serinin ACF ve PACF grafikleri de incelenmiştir. AR için $p$ değerini PACF, MA için q değerini ise ACF vermektedir. Şekil 1'de görüldüğü gibi ACF'de ve PACF'de geometrik bir azalış söz konusu değildir. Sadece ilk gecikme değerlerinin sınırlar dışında olduğu, diğer gecikme değerlerinin ise sinırlar içinde yer aldığı ve katsayıların birbirleri ile iliş̧kisinin olmadığı anlaşıldığından, seride otokorelasyon ve kısmi otokorelasyon bulunmamaktadır. Bu nedenle de serinin durağan olduğu sonucuna ulaşılmıştır. Buna göre, Şekil 2'de fiyat serisi için PACF, AR için, ACF'de MA için olmak üzere 1. gecikmeye ait ilişki önemli olduğundan modelin ARMA $(1,1)$ biçiminde kurulabileceği değerlendirilmiştir.

Çizelge 1. Çam balı fiyat serisine ait ADF birim kök testi sonucu

\begin{tabular}{lccc}
\hline & Düzey & t-istatistiği & p-değeri \\
\hline ADF test istatistiği & & $-4,03838$ & \\
\cline { 1 - 3 } Testin kritik değerleri & $\% 1$ & -4.374307 & \multirow{2}{*}{$0,007674^{* * *}$} \\
& $\% 5$ & -3.603202 & \\
\hline$* * * 0,01$ d & -3.238054 & \\
\hline
\end{tabular}

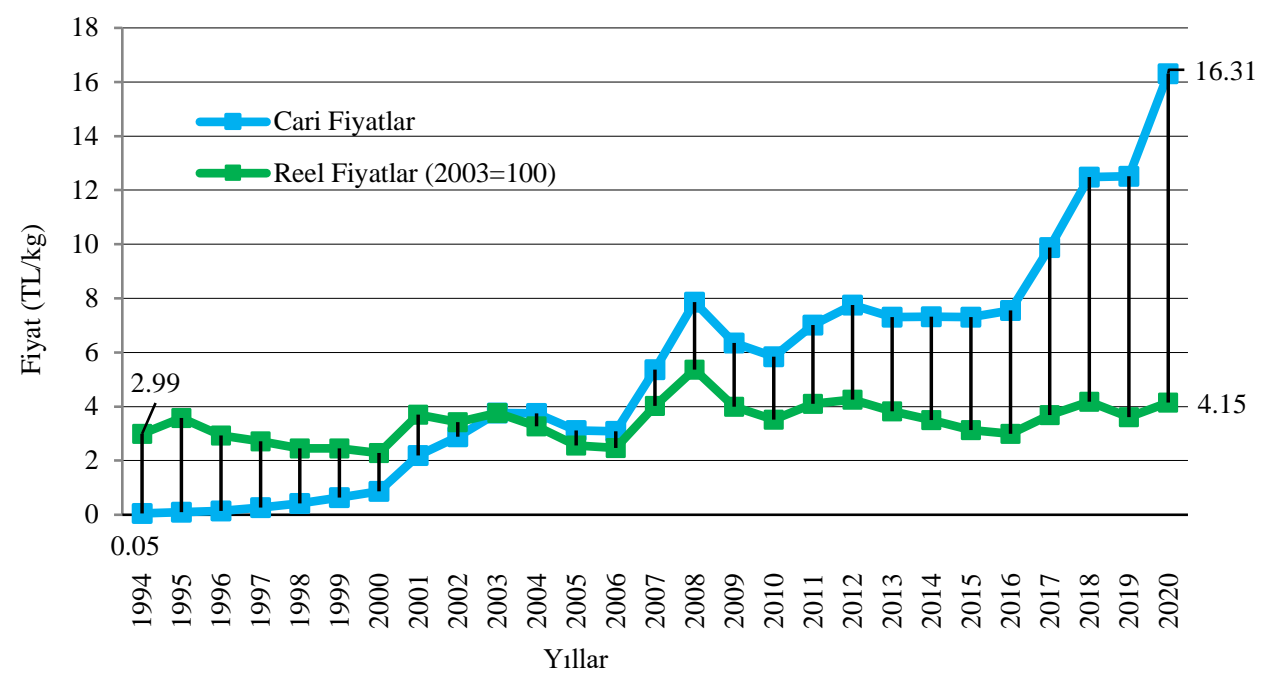

Şekil 1. Ticaret borsaları süzme çam balı ağırlıklı ortalama üretici satış fiyatları (TL/kg) (*1994-2005 yılları arasındaki parasal değerlerden 6 sıfır atılarak dönüşümü yapılmışıtır)

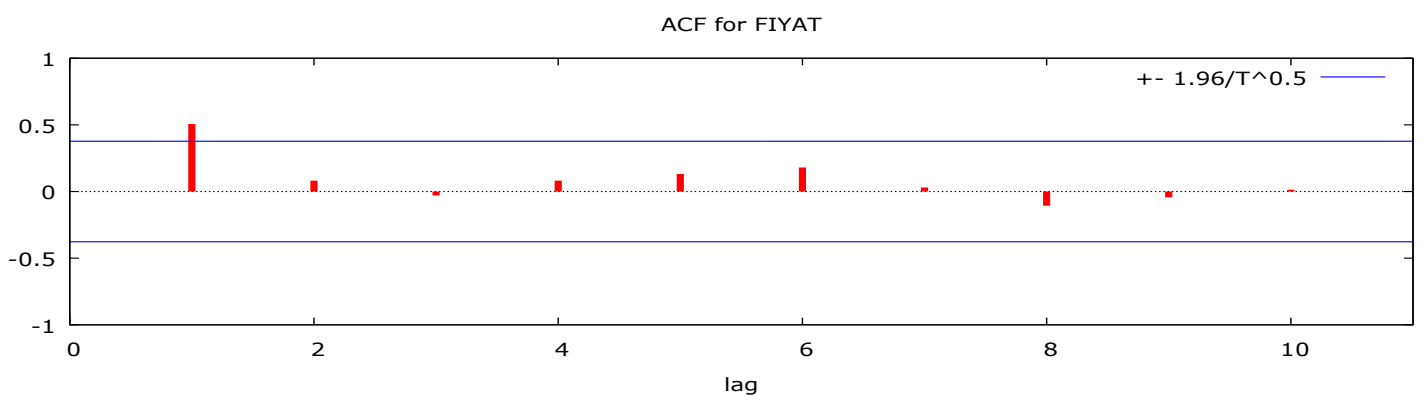

PACF for FIYAT

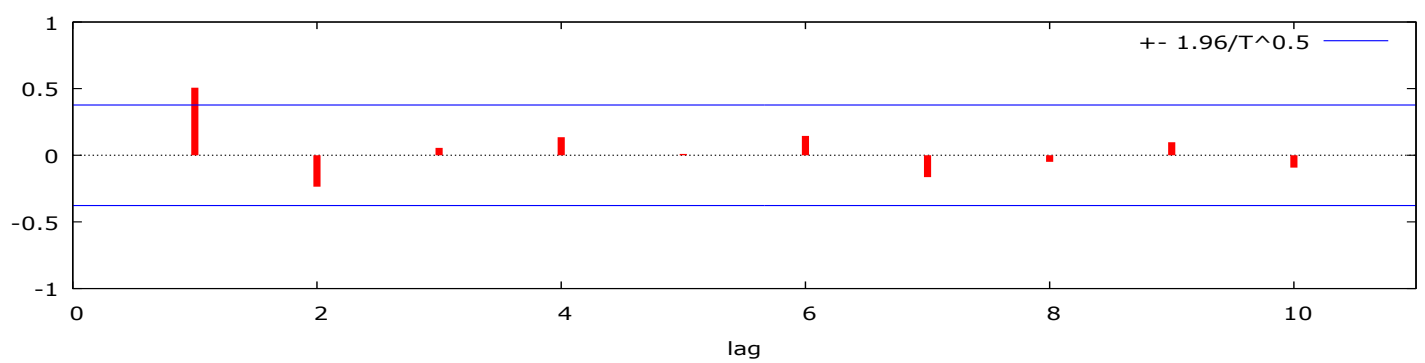

Şekil 2. Çam balı fiyat serisinin ACF ve PACF dağılımı 
$\mathrm{Bu}$ değerlendirmenin dişında birçok farklı ARMA modelleri de araştırılarak en iyi istatistiksel sonuç veren ARMA $(1,2)$ modeli elde edilmiştir. ARMA $(1,2)$ model sonuçlarına göre, tüm değişkenler istatistiksek olarak anlamlı bulunmuştur. Ljung-Box istatistiğine göre (4. gecikme düzeyinde) 0,05 hata payı ile otokorelasyon sorunu tespit edilmemiş $(p=0,18>0,05)$, fiyat hareketlerinin rassal bir seyir izlediği belirlenmiştir. Modelin MAPE değeri \%14,65 olup belirtilen sınır (\%20) içerisinde kalmaktadır. Theil Eşitlik Katsayısı 0,80 olarak hesaplanmış ve 1'den küçük olması nedeni ile çam balı üretici fiyat öngörüsü için uygun bir model olduğu ortaya çıkmıştır. Modele ilişkin sonuçlar Çizelge 2'de yer almaktadır.

Ancak modelden elde edilen kalıntı değerlerinin durağan olup olmadığını belirledikten sonra modelin doğruluğuna karar vermek amacıyla modele ait kalıntı değişkeni oluşturularak ADF Birim Kök testi uygulanmış ve " $\mathrm{H}_{0}=$ birim kök vardır" hipotezi reddedilmiştir (Çizelge 3).

Diğer taraftan model kalıntı değerlerinin dağılımını belirlemek amacıyla Shapiro-Wilk normallik testi yapılmış ve hataların normal dağıldığ $(Z=0,96322, p=0,43625>0,05)$ belirlenmiştir.

ARMA $(1,2)$ modelinin kalıntı değerlerinin ACF ve PACF grafiği incelendiğinde; dalgalanmanın olmadığı,

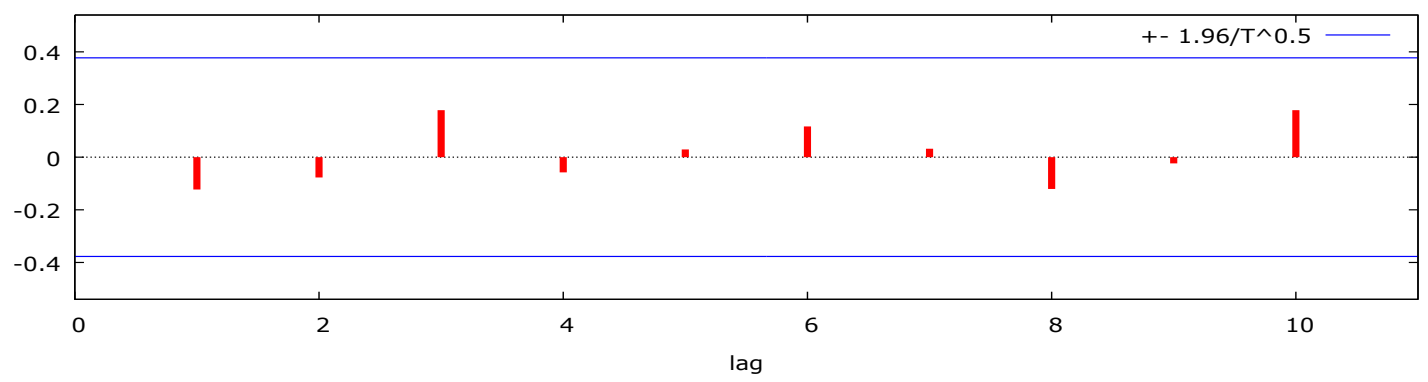

lag

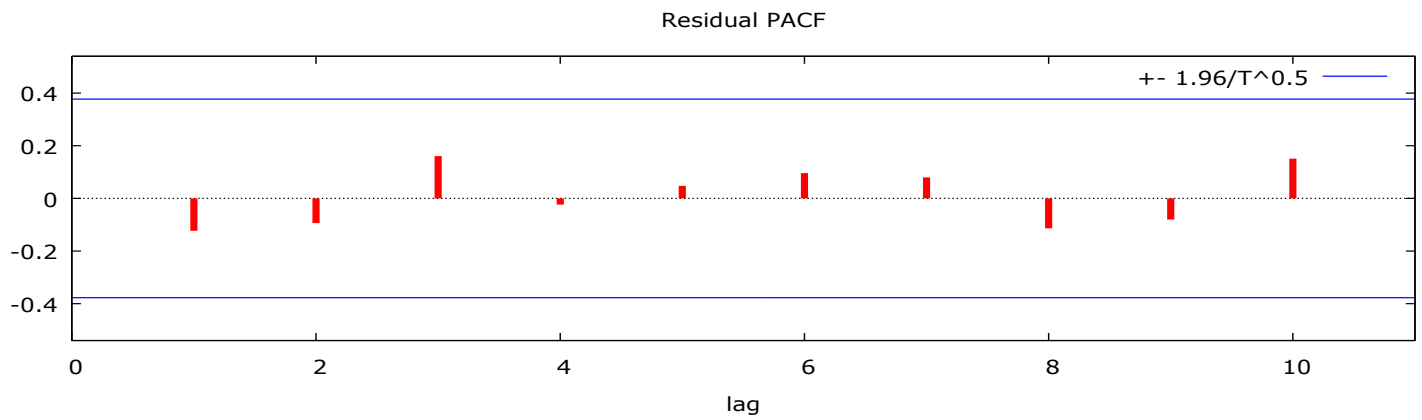

Şekil 3. ARMA $(1,2)$ modeli kalıntı değerlerine ilişkin ACF ve PACF dağılımı

Çizelge 2. Çam balı fiyat serisine ait ARMA $(1,2)$ modeline ilişkin sonuçlar

\begin{tabular}{|c|c|c|c|c|}
\hline & Katsay1 & Standart Hata & $\mathrm{Z}$ & p-değeri \\
\hline Sabit & 3,43272 & 0,232642 & 14,7554 & $<0,0001^{* * * *}$ \\
\hline $\mathrm{AR}(1)$ & $-0,41847$ & 0,222787 & $-1,8783$ & $0,0603^{*}$ \\
\hline MA (1) & 1,39154 & 0,378709 & 3,6744 & $0,0002^{* * *}$ \\
\hline MA (2) & 0,929004 & 0,549234 & 1,6915 & $0,0908^{*}$ \\
\hline $\mathrm{AIC}$ & 55,49185 & MAPE & 14,653 & \\
\hline $\mathrm{BIC}$ & 61,97103 & Theil's U & 0,79839 & \\
\hline HQC & 57,41845 & Ljung-Box Q (4) & 1,79668 & 0,1801 \\
\hline
\end{tabular}

Çizelge 3. Fiyat modeline ilişkin kalıntı değerlerinin durağanlık testi

\begin{tabular}{ccc} 
& ADF test istatistiği & p-değeri \\
\hline Fiyat Modelinin Kalıntı Değeri & $-5,97444$ & $0,0002453^{* * *}$ \\
\hline$* * * 0,01$ düzering
\end{tabular}

anlamlılık sınırlarının aşılmadığı ve öngörü için uygun düzeylere sahip olduğu görülmektedir (Şekil 3). Bu ilişkin en uygun modelin ARMA $(1,2)$ olduğu urılıklı ortalama üretici reel satış fiyat verilerinden 2021-2025 dönemi için öngörü yapılmıştır. Çam balı üretici reel satış fiyatları $(2003=100)$ gerçekleşme ongörü grafiği Şekil 4'te gösterilmiştir.

edilen sonuçlarına göre; ticaret borsalarında işlem itibaren dalgalı bir yapı izleyerek azalma eğilimi göstereceğ belirlenmiştir. 2023 yılında $3,26 \mathrm{TL} / \mathrm{kg}$ ile en düşük düzeye ulaştıktan sonra 2024 y1lında \%7,36 oranında artarak 3,50 $\mathrm{L} / \mathrm{kg}$ seviyesine gelmesi beklenen fiyatların, 2025 yılında oranında tekrar azalacağ 1 ve 3,40 TL/kg olacağ öngörülmüştür (Şekil 4). Gelecek beş yıl sonunda piyasada uşması beklenen 3,40 TL/kg'lik fiyat ortalamasının ise, en son gerçekleşen 2020 yılı fiyat ortalamasından $(4,15 \mathrm{TL} / \mathrm{kg})$ $\% 18,07$ oranında daha az olduğu hesaplanmıştır. Tasilmaktadır. 


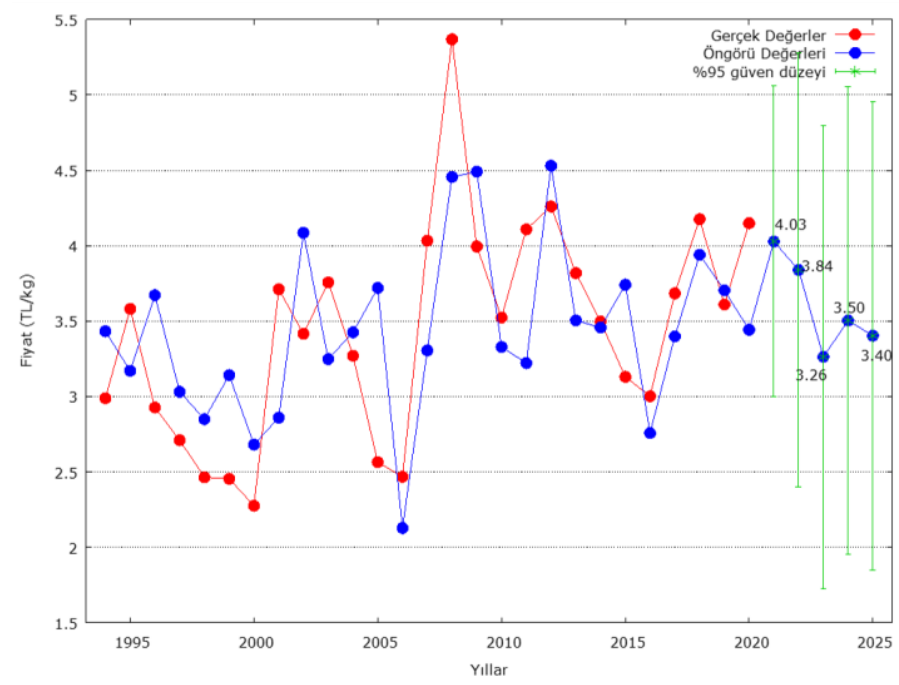

Şekil 4. Çam balı üretici reel satış fiyatları $(2003=100)$ gerçekleşme ve öngörü grafiği Kaynak: Gerçek değerler İTB, ATB ve MTB yıllık bültenlerinden oluşturulmuştur (ITB, ATB, MTB, 2021).

\section{Tartışma ve sonuç}

Bu araştırmada İTB, ATB ve MTB'de tescil edilen süzme çam balı üretici satış fiyatları ağırlıklı ortalamasına ait 19942020 (27 yıl) yılları arasındaki dönemi kapsayan veriler esas alınarak gelecek beş yıllık reel fiyat değerleri $(2003=100)$ Box-Jenkins (ARMA) yöntemi kullanılarak öngörü yapılmıştır. Oluşturulan modellerden en iyi öngörü başarı ölçütlerine sahip olan ARMA $(1,2)$ modeli kullanılmıştır. Yapılan çözümlemelere göre 2021 yılından itibaren çam balı üretici reel fiyatlarının düşeceği beklenmektedir. 2020 yılında $4,15 \mathrm{TL} / \mathrm{kg}$ olan ortalama reel fiyatın $\% 18,07$ oranında azalarak 2025 yılında 3,40 TL/kg seviyesine ineceği öngörülmüştür.

Girdi fiyatları artarken üreticinin bal satış fiyatının değişmemesi bir yana daha da düşmesi arıcılık işletmelerinin bal üretimini bırakmasına yol açan önemli bir faktördür. Çam balı piyasasındaki fiyat değişimleri ve belirsizlikler sektörde beklenen olumlu gelişmeleri engellemektedir. $\mathrm{Bu}$ nedenle piyasanın öncelikli hedefi fiyat istikrarının sağlanması olmalıdır. Dolayısıyla, sektöre güvenilir bilgi sağlayacak, fiyatları dengeye getirecek bir sistem gereksinimi ortaya çıkmıştır. Tarım ürünlerindeki böyle bir ihtiyacın giderilmesi amaciyla 17.02.2005 tarihli ve 25730 say1lı Resmi Gazete'de yayınlanan 5300 sayılı Tarım Ürünleri Lisanslı Depoculuk Kanunu çıkarılmıştır (RG, 2005). Sonrasında ise 5300 sayılı Kanun çerçevesinde lisanslı depo işletmecilerince oluşturulan elektronik ürün senetleri ile vadeli işlem sözleşmelerinin ticaretinin yürütülmesini gerçekleştirmek üzere 06 Nisan 2017 tarih ve 30030 sayılı Resmî Gazete'de Türkiye Ürün İhtisas Borsası (TÜRİB) kurulmasına izin verilmiştir (RG, 2017).

Çam balı üretiminin fazla olduğu dönemde ürünün depolanması, az olduğu dönemde ise piyasaya arz edilmesine olanak veren ve ürün sahiplerinin mallarının kalitesini koruyan bir depolama sistemine gerek duyulmaktadır. Çam balının da lisanslı depolarda depolanabilecek ürün kapsamına alınıp, lisanslı depolarda bulunan ürünleri temsil eden elektronik ürün senedi ile kayıt altına alınarak TÜRİB'de işlem görmesi son derece önemlidir. Bununla birlikte, ürün sinıflarının yetkili laboratuvarlar tarafindan belirlenmesini sağlayan, ürünlerin mülkiyetini temsil eden, finansmanını, satışını ve teslimini gerçekleştirmeye yarayan ayrıca ticaretini kolaylaştıran bir oluşumun çam balı sektöründe yer alan tüm paydaşlar açısından olumlu yansımalarının olacağı söylenebilir.

Türkiye'de odun dışı orman ürünleri arasında ihracat açısından önemli bir yer tutan çam balı reel fiyatlarının öngörüsünün yapıldığı bu tür araştırmaların fiyat belirsizliklerinin azaltılması ve ileride oluşabilecek fiyatlar hakkında bilgi sahibi olunması gibi getirdiği yararların yanında üretim planlarının da sağlıklı bir şekilde oluşturulmasına olanak sağlayacağı düşünülmektedir.

\section{Açılklama}

Bu makale Orman Genel Müdürlüğü, Ege Ormancılık Araştırma Enstitüsü Müdürlüğü’nce diğer çalışmalı projeler kapsamında desteklenen ve Ege Üniversitesi Fen Bilimleri Enstitüsü Tarım Ekonomisi Anabilim Dalı'nda yürütülen “Ürün İhtisas Borsasının Odun D1şı Orman Ürünlerine Uygulanabilirliği Üzerine Bir Araştırma: Çam Balı Örneği" isimli doktora tezinin bir bölümüdür. Araştırmaya verdikleri katkılar için İzmir Ticaret Borsası'na, Aydın Ticaret Borsası'na ve Muğla Ticaret Borsası'na teşekkür ederiz.

\section{Kaynaklar}

Akay, E.Ç., Topal, K.H., Kızıllarsan, S., Bülbül, H., 2019. Türkiye konut fiyat endeksi öngörüsü: ARIMA, rassal orman ve arima-rassal orman. PressAcademia Procedia, 10(1): 7-11. DOI: 10.17261/Pressacademia.2019.1134.

Akdağ, M., Yiğit, V., 2016. Box-Jenkins ve yapay sinir ağı modelleri ile enflasyon tahmini. Atatürk Üniversitesi İktisadi ve İdari Bilimler Dergisi, 30(2): 269-283.

Akyol, A., Cazağ, S.N., 2018. Arıcılığın geliştirilmesine yönelik arı yetiştiricilerinin beklenti ve değerlendirmeleri. $1^{\text {st }}$ International Symposium on Silvopastoral Systems and Nomadic Societies in Mediterranean Countries, 22-24 October, Isparta, Turkey, pp. 329340.

Arslan, M.,B., 2019. Basra Böceği (Marchalina hellenica Genn.)'nin konuk olduğu ve olmadığı kızılçam (Pinus brutia ten.) ağaçlarının kabuk ve ibrelerinin bazı ekstraktif bileşenlerinin incelenmesi, Doktora Tezi, Isparta Uygulamalı Bilimler Üniversitesi Lisansüstü Eğitim Enstitüsü, Isparta.

Ataseven, B., 2013. Yapay sinir ağları ile öngörü modellemesi. Öneri Dergisi, 10(39): 101-115.

ATB, Aydın Ticaret Borsası, Yıllık bültenler 2021. https://aydinticaretborsasi.org.tr/. Erişim: 10.04.2021. 
Bacandritsos, N., Saitanis, C., Papanastasiou, I., 2004. Morphology and life cycle of Marchalina hellenica (Gennadius) (Hemiptera: Margarodidae) onpine (Parnis Mt.) and fir (Helmos Mt.) forests of Greece. Annales de la Société Entomologique deFrance, 40(2): 169176, DOI: 10.1080/00379271.2004.10697413

Bars, T., Uçum, İ., Akbay, C., 2018. ARIMA modeli ile Türkiye findık üretim projeksiyonu. Kahramanmaraş Sütçü İmam Üniversitesi Tarım ve Doğa Dergisi, 21 (Özel Sayı): 154-160. DOI: 10.18016/ksutarimdoga.v21i41625.473029.

Bayramoğlu, M.M., 2018. Türkiye'de oduna dayalı orman ürünleri üzerine bir araștırma: Zaman serisi analizi. Artvin Çoruh Üniversitesi Orman Fakültesi Dergisi, 19(1): 18-26, ISSN:21461880, e-ISSN: 2146-698X,. DOI: 10.17474/artvinofd.333344.

Berk, A., Uçum, İ., 2019. "Türkiye'nin nohut üretiminin ARIMA modeli ile tahmini. Iğdır Üniversitesi Fen Bilimleri Enstitüsü Dergisi, 9(4): 2284-2293. DOI:10.21597/jist.544619.

Burucu, V., Gülse Bal, H. 2017. Türkiye'de arıcılığın mevcut durumu ve bal üretim öngörüsü. Tarım Ekonomisi Araştırmaları Dergisi, 3(1): 28-37.

Caner, C.B., Engindeniz, S., 2020. Türkiye'de pamuk üretiminin ARIMA modeli ile tahmini. Tarım Ekonomisi Dergisi, 26(1): 63-70. DOI: $10.24181 /$ tarekoder.681079

Çamoğlu, S, Akıncı, M., 2012. Türkiye'de sektörel banka kredilerinin gelişimi: Bir zaman serisi analizi. Yönetim ve Ekonomi: Celal Bayar Üniversitesi İktisadi ve İdari Bilimler Fakültesi Dergisi, 19(1): 193 210.

Çakan, V., 2020. Türkiye yaş incir üretimi ve kuru incir ihracatı için öngörü: Arima modeli yaklaşımı. Tekirdağ Ziraat Fakültesi Dergisi, 17(3): 357-368. DOI: 10.33462/jotaf.684893.

Çelik, Ş., 2015. Türkiye'de bal üretiminin zaman serileri ile modellenmesi. Sakarya Üniversitesi Fen Bilimleri Enstitüsü Dergisi, 19(3): 377-382

Çevrimli, M., Sakarya, E., 2019. Arıcılık ekonomisine giriș ve saha verileri ile bir değerlendirme. Veteriner Farmakoloji ve Toksikoloji Derneği Bülteni, 10(1): 40-48. ISSN:1309-4769.

Çevrimli, M., Arıkan, M., Tekindal, M., 2020. Honey price estimation for the future in Turkey; example of 2019- 2020. Ankara Üniversitesi Veteriner Fakültesi Dergisi, 67(2): 143-152. DOI: 10.33988/auvfd.570790.

Çukur, F., Kızılaslan, N., Kızılaslan, H., 2019. Honey production and marketing in Tokat province, 3rd International Conference on Food and Agricultural Economics, 25-26 ${ }^{\text {th }}$ April, Alanya, Turkey, pp. 224-234.

Dickey, D.A., Fuller, W.A., 1981. Likelihood ratio statistics for autoregressive time series with a unit root. Econometrica, 49(4): 1057-1072.

EİB, 2021. Ege İhracatçı Birlikleri, Su ürünleri ve hayvansal mamüller aylık raporları, Ocak-Aralık 2020, http://www.eib.org.tr/, Erișim: 01.04.2021.

Erturan, M.B., 2017. Zaman serileri için optimize ARIMA - YSA Hibrit modeli ve finansal Zaman serileri ile örnek uygulamalar. Doktora tezi, Akdeniz Üniversitesi, Sosyal Bilimler Enstitüsü, Antalya.

Esen, N., 2016, Türkiye'nin ağaç ve orman ürünleri ihracat ve ithalat değerlerinin Box-Jenkins ve yapay sinir ağları yöntemleri ile tahmin edilmesi ve karşılaştırılması. Doktora tezi, Karadeniz Teknik Üniversitesi, Fen Bilimleri Enstitüsü, Trabzon.

Göksu, E., Adanacioğlu, H., 2018. Türkiye'de odun dişı orman ürünlerinde doğrudan pazarlama. Türkiye Ormancılık Dergisi, 19(2): 210-218. DOI: 10.18182/tjf.414125.

Güler, D., Saner, G., Naseri, Z., 2017. Yağlı tohumlu bitkiler ithalat miktarlarının ARIMA ve yapay sinir ağları yöntemleriyle tahmini. Balkan ve Yakın Doğu Sosyal Bilimler Dergisi, 3(1): 60-70.

İTB, İzmir Ticaret Borsası, Yıllık Bültenler 2021. https://itb.org.tr, Erișim: 21.03.2021

Kadirhanoğulları, İ., 2016. Iğdır ili arıcılarının sosyo-ekonomik durumu. Uludağ Arıcılık Dergisi, 16(1): 2-11. DOI: 10.31467/uluaricilik.379245.

Kayacan, B., Kara, O., Ucal, M.Ș., Öztürk, A., Bali, R., Koçer, S., Kaplan, E., 2013. An econometric analysis of imported timber demand in Turkey. Journal of Food, Agriculture \& Environment, 11(1): 791-794.
Korkmaz, M., 2016. Muğla Kızılçam Ormanlarında Arıcılık: SosyoEkonomik Değerlendirme, Muğla Kızılçam Ormanlarında Arıcılık Ormancılık İlişsileri (Ed: Avcı, M., Korkmaz, M.), MAYBİR, ISBN 978-605-66673-0-5, s: 122-142.

Kurt, R., Imren, E., Cabuk, Y., Karayilmazlar, S., 2018. Estimation of global wood pellet production as a renewable energy source by ARIMA method. Fresenius Environmental Bulletin, 27(7): 51475152.

Kurt, R, Karayılmazlar, S., 2019. Türkiye mantar üretimi ve ARIMA (Box-Jenkins) ile projeksiyonu. Ormancılık Araştırma Dergisi, 6(1): 72-76. DOI: 10.17568/ogmoad.461534.

Ljung, G.M.,. Box, G.E.P., 1978. On a measure of lack of fit in timeseries models. Biometrika, 65(2): 297-303. https://doi.org/10.1093/biomet/65.2.297.

MTB, Muğla Ticaret Borsası, Yıllık bültenler 2021 http://www.muglaticaretborsasi.org.tr, Erișim: 01.04.2021

OGM, 2021., Orman Genel Müdürlüğü, Ormancılık İstatistikleri 2019, https://www.ogm.gov.tr, Erișim: 21.03.2021.

Onuç, Z., Yanar, A., Saner, G., Güler, D., 2019. Arıcılık faaliyetinin ekonomik yönü üzerine bir analiz: İzmir-Kemalpaşa ilçesi örneği/Türkiye. Ege Üniversitesi Ziraat Fakültesi Dergisi, 56(1): 7 14, DOI: $10.20289 /$ zfdergi.420370.

Oruç, K.O., Eroğlu, Ş.Ç., 2017. Isparta ili için doğal gaz talep tahmini. Süleyman Demirel Üniversitesi İktisadi ve İdari Bilimler Fakültesi Dergisi, 22(1): 31-42.

Özer, O.O., İlkdoğan, U., 2013. Box-Jenkins modeli yardımıyla dünya pamuk fiyatının tahmini. Namık Kemal Üniversitesi Tekirdağ Ziraat Fakültesi Dergisi, 10(2): 13-20.

Özer, O.O., Yavuz, G.G., 2014. Box-Jenkins modeli yardımıyla findık fiyatının tahmini. XI. Ulusal Tarım Ekonomisi Kongresi, 03-05 Eylül, Samsun, pp. 1689-1694.

Öztürk, C., Subaşı, O.S., Uysal, O., Seçer, A., Alemdar, T., Ören, M.N., 2014. Akdeniz Bölgesinde Arıcılık İssletmelerinin Teknik ve Ekonomik Yapısının Belirlenmesi. Proje Sonuç Raporu, TAGEM, TEPGE Yayın No:254, ISBN: 978-605-9175-24-1, 39 s.

RG, 2005. Tarım Ürünleri Lisanslı Depoculuk Kanunu (5300 sayılı). T.C. Resmi Gazete, 25730, 17 Şubat 2005.

RG, 2017. Türkiye Ürün İhtisas Borsası Anonim Şirketinin Kurulmasına Izin Verilmesi Hakkında Karar T.C. Resmi Gazete, 30030, 06 Nisan 2017.

Saner, G., Adanacioğlu, H., Naseri, Z., 2018. Türkiye'de bal arzı ve taleb için öngörü. Tarım Ekonomisi Dergisi, 24(1): 43-51, DOI 10.24181/tarekoder.449992.

Şen, G., Güngör, E. 2018. Determination of the seasonal effect on the auction prices of timbers and prediction of future prices. Journal of Bartin Faculty of Forestry, 20(2): 266-277.

Şengül, Z., 2020. Ege bölgesinde arıcılık yapan işletmelerin sürdürülebilirlik yönünden değerlendirilmesi. Doktora tezi, Ege Üniversitesi, Fen Bilimleri Enstitüsü, İzmir.

Tatoğlu, F.Y., 2018. Panel Veri Ekonometrisi. Beta Basım Yayım Dağıtım A.S., Yayın No:3802, İsletme-Ekonomi Dizisi: 979, İstanbul, ISBN: 978-605-242-281-6, $334 \mathrm{~s}$

TÜİK, 2021., Türkiye İstatistik Kurumu, Hayvansal üretim istatistikleri (y1llik), https://data.tuik.gov.tr, Erişim: 26.03.2021.

Uçum, İ., 2016. ARIMA modeli ile Türkiye soya üretim ve ithalat projeksiyonu. Tarım Ekonomisi Arastırmaları Dergisi, 2(1): 24-31.

Ülgentürk, S., Civelek, H.S., Şahin, Ö., Evren, H., Sarıbaşak, H., 2012. Çam Pamuklu Koşnili Biti Marchalina hellenica Genn. (Hemiptera: Margarodidae)'nın Biyo-Ekolojisi, Ege ve Akdeniz Bölgesindeki Yayılış Alanları. TÜBİTAK-TOVAG-108O359 Proje Sonuç Raporu, $144 \mathrm{~s}$

Ülgentürk, S, Özdemir, İ., Kozar, F., Kaydan, M., Dostbil, Ö., Sarıbaşak, H., Civelek, H., 2014. Honeydew producing insect species in forest areas in Western Turkey. Türkiye Entomoloji Bülteni, 3(4): 125133, ISSN 2146-975X.

Yalta, T.A., 2011. Ekonometri 2 Ders Notları, TÜBA, Türkiye Bilimler Akademisi, Açık Ders Malzemeleri Projesi, Sürüm 2.0, http://yalta.etu.edu.tr, Erişim: 01.04.2021, $180 \mathrm{~s}$.

Yıldız, M., Atıș, E., 2019. Türkiye organik incir ihraç fiyatının arma yöntemi ile tahmini. Tarım Ekonomisi Dergisi, 25(2): 141-147. DOI: $10.24181 /$ tarekoder.583972. 